\title{
Solitary extramedullary plasmacytoma of the maxillary antrum and orbit presenting as acute bacterial orbital cellulitis
}

\author{
S P Kelly, I C Lloyd, H Anderson, P W Joyce, A Pace-Balzan
}

\begin{abstract}
Orbital involvement by plasma cell tumours is rare. Orbital tumours do not generally present as an acute orbital inflammatory disease in adults, though tumours such as rhabdomyosarcoma may cause clinical signs similar to an acute orbital cellulitis in children. We describe a patient with bacterial orbital cellulitis and sinusitis who was found to have an extramedullary plasmacytoma of the maxillary antrum and orbit and coexisting testicular seminoma.
\end{abstract}

A 56-year-old previously healthy male, presented with a one-week history of right-sided orbital pain, blurred vision, and vertical diplopia. Visual acuity (Snellen) was $6 / 9$ in the right eye and $6 / 6$ in the left. The right eye showed $2 \mathrm{~mm}$ of ptosis, $3 \mathrm{~mm}$ of proptosis, and $3 \mathrm{~mm}$ of downward displacement of the globe. There was a fluctuant mass at the outer canthus with associated periorbital oedema and some conjunctival chemosis (Fig 1). There was a right relative afferent pupil defect and restriction of right up gaze. Funduscopy showed normal appearances. The left eye was normal. The right nostril was discharging pus, and right infraorbital nerve anaesthesia was present. The sublingual temperature was $38^{\circ} \mathrm{C}$.

Plain $x$ rays showed opacity of the right antrum. Bacterial orbital cellulitis secondary to sinusitis was suspected. Intravenous antibiotics were prescribed, following which there was gradual improvement in symptoms and orbital signs. A maxillary antral washout was carried out and swabs from the right antrum grew Steptococcus pneumoniae. A computed tomogram of the maxilla and orbit revealed an extensive mass filling the right maxillary antrum, eroding the medial and lateral walls of the antrum and orbital floor, with tumour extending upwards into the orbit and encompassing the inferior aspect of the optic nerve (Fig 2). At the most

\footnotetext{
Mospital

S P Kelly

I C Lloyd

$\mathrm{PW}$ Joyce
}

Department of Medical Oncology, University of Manchester

$\mathrm{H}$ Anderson

ENT Department, Manchester Royal Infirmary

A Pace-Balzan

Correspondence to: Mr I C Lloyd, Manchester Royal Eye Hospital, Oxford Road, Manchester M13 9WH.

Accepted for publication 6 December 1990

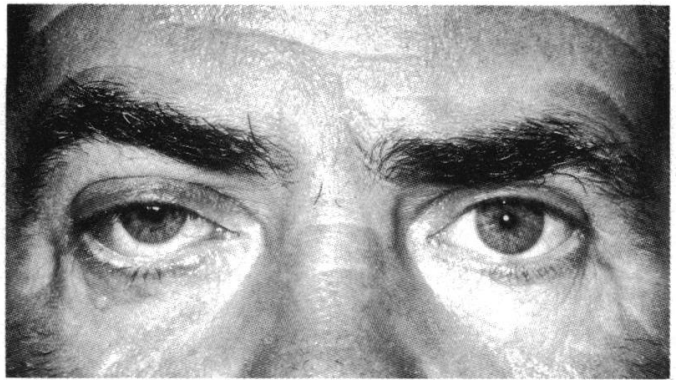

Figure 1 Facial view showing right-sided ptosis and conjunctival hyperaemia.

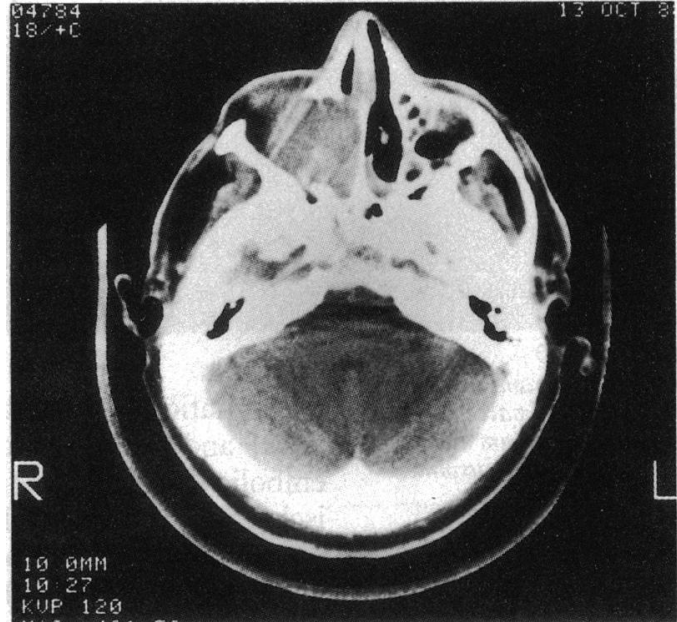

Figure $2 C T$ scan: coronal section through maxillary sinuses revealing an opaque right antrum with extensive destruction of its medial and lateral walls.

posterior aspect the pterygoid plates were involved, but the mass did not extend through the base of the skull. Antral biopsies revealed large numbers of plasmacytoid cells, plasma cells, and less differentiated forms with large nucleoli. Mitoses, pleomorphism, and apoptotic cells were all present (Fig 3). Extramedullary plasmacytoma was diagnosed.

Oncology consultation revealed an asymptomatic testicular mass. Further investigations showed no evidence of multiple myeloma on skeletal $x$ rays, and normal findings for serum immunoglobulins, electrophoresis, light chain urinary excretion, bone marrow aspiration, and trephine biopsy. A right orchidectomy was subsequently performed. Histologically it was an anaplastic seminoma. Radiotherapy to the right maxillary antrum, orbit, and para-aortic areas was given. The patient remains well at 18 months follow up.

\section{Discussion}

Multiple myeloma is a disseminated plasma cell dyscrasia characterised by marrow infiltration, multiple erosive bony lesions, and the production of a monoclonal protein. Ocular manifestations of multiple myeloma such as corneal and conjunctival deposition of crystals, and retinal and proteinaceous pars plana cysts, are due to the hypergammaglobulinaemia and/or changes in blood rheology..$^{2}$ Infiltration of the uveal tract can also occur. ${ }^{13}$

Solitary plasma cell tumours of bone or of soft tissues (extramedullary plasmacytoma) can occur independently of multiple myeloma. ${ }^{+}$Extra- 


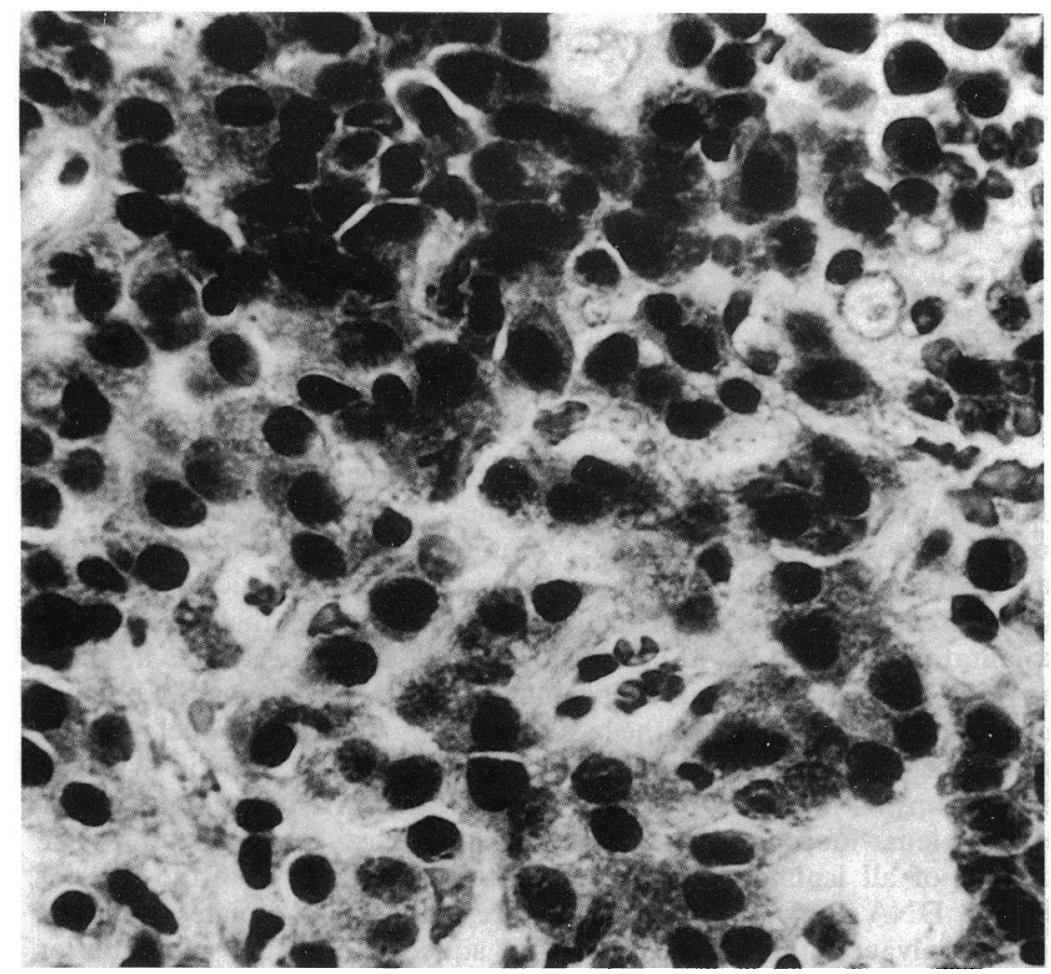

Figure 3 Histology of antral plasmacytoma showing pleomorphic plasma cells and plasmacytoid cells, some containing large nucleoli. (H and $E, \times 250$.

medullary plasmacytomas represent only $3 \%$ of plasma cell neoplasms and occur mostly in the upper respiratory tract. Those affected have a mean survival of 192 months compared with a mean survival of 30 months for multiple myeloma. ${ }^{4}$

Extramedullary plasmacytomas of the orbit have been described in 10 patients. ${ }^{56}$ Prolonged follow-up or complex investigations are required to establish that the orbital disease is not an early manifestation of multiple myeloma. Over 30 cases have been recorded of multiple myeloma involving the orbit, most of which had evidence of disseminated disease on presentation. ${ }^{156}$ Orbital involvement usually presents with slowly progressive proptosis. Our patient, in marked contrast, presented with acute bacterial orbital cellulitis. De-Smet and Rootman described a patient with known systemic multiple myeloma who presented with a possible orbital cellulitis. ${ }^{6}$ Frontal sinus biopsy confirmed malignant plasma cells, and despite chemotherapy death occurred from intracranial extension. Mustoe et al described a patient with a febrile sinus infection, unresponsive to seven weeks of intravenous antibiotics, in whom an eventual histological diagnosis of plasmacytoma was made.? That patient responded well to radiotherapy, the treatment of choice for solitary plasmacytomas. ${ }^{8}$

Our case emphasises the importance of a computerised tomogram of paranasal sinuses and orbits and of obtaining tissue for histological study - for example by paranasal sinus trephination - in the management of such patients.

A second rare type of neoplasm, a testicular seminoma, was also discovered in this patient. Histologically the two tumours were completely distinct. Simultaneous presentation of multiple tumours is recognised, though unusual. An enhanced susceptibility to mitotic lesions has been postulated. A specific oncogene may be responsible.

The ophthalmologist managing a patient with an orbital neoplasm requires the combined skills of a multidisciplinary team. Oncology, radiotherapy, otolaryngology, neurosurgery, neuroradiology, and orbital pathology services may all be required.

We are grateful to Dr R E Bonshek, Department of Ophthalmic Pathology, and to Dr D Martin, Department of Diagnostic Radiology, at the University of Manchester for their expert help. The patient was under the care of Mr K B Mills, FRCS.

1 Knapp AJ, Gartner S, Henkin P. Multiple myeloma and its ocular manifestations. Surv Ophthalmol 1987; 31: 343-51.

2 Foulds WS. 'Blood is thicker than water.' Some haemorheological aspects of ocular disease. Eye 1987; 1: 343-63.

3 Shankin EP, Augsburger J, Eagle RC, et al. Multiple myeloma involving the iris. Arch Ophthalmol 1988; 106: 524-6.
inting

4 Bergsagel DE, Rider WD. Plasma cell neoplasms. In: DeVita VT, Hellman S, Rosenberg SA, eds. Cancer Principles and practice of oncology. 2nd ed. Philadelphia: Lippencott, 1985; 1753-61.

5 Rodman HI, Font RL. Orbital involvement in multiple myeloma. Arch Ophthalmol 1972; 87: 30-5.

6 De-Smet MD, Rootman J. Orbital manifestations of plasmacytic lymphoproliferations. Ophthalmology 1987; 94: 995-1003.

7 Mustoe TA, Fried MP, Goodman ML, Kelly JH, Strome M. Osteosclerotic plasmacytoma of maxillary bone (orbital floor). F Laryngol Otol 1984; 98: 929-38.

8 Greenberg P, Parker RG. Fu YS, Abemayor E. The treatment of solitary plasmacytoma of bone and extramedullary plasmacytoma. Am f Clin Oncol 1987; 10: 199-204. 